\title{
REVIEW
}

\section{Practical Considerations for the Use of Subcutaneous Treatment in the Management of Dyslipidaemia}

Franck Boccara (D) Ricardo Dent - Luis Ruilope $\cdot$ Paul Valensi

Received: January 9, 2017 / Published online: July 17, 2017

(C) The Author(s) 2017. This article is an open access publication

\begin{abstract}
Suboptimal drug adherence represents a major challenge to effective primary and secondary prevention of cardiovascular disease. While adherence is influenced by multiple considerations, polypharmacy and dosing frequency appear to be rate-limiting factors in patient
\end{abstract}

Enhanced content To view enhanced content for this article go to http://www.medengine.com/Redeem/ 9ED8F06068C864B8.

F. Boccara $(\bowtie)$

Cardiology Unit, Hôpital Saint-Antoine, AP-HP,

Hôpitaux de l'Est Parisien, Paris, France

e-mail: franck.boccara@aphp.fr

F. Boccara

INSERM, UMR_S 938, Faculty of Medicine,

Sorbonne Universities, UPMC University Paris 06,

Paris, France

R. Dent

Amgen (Europe) GmbH, Zug, Switzerland

Present Address:

R. Dent

Esperion Therapeutics Inc, Ann Arbor, MI, USA

L. Ruilope

Institute of Research, Hypertension Unit, Hospital

12 de Octubre, Madrid, Spain

P. Valensi

Department of

Endocrinology-Diabetology-Nutrition, Jean Verdier

Hospital, APHP, CRNH-IdF, CINFO, Paris Nord

University, Bondy, France satisfaction and subsequent adherence. The cardiovascular and metabolic therapeutic areas have recently benefited from a number of advances in drug therapy, in particular protease proprotein convertase subtilisin/kexin type 9 (PCSK9) inhibitors and incretin-based therapies, respectively. These drugs are administered subcutaneously and offer efficacious treatment options with reduced dosing frequency. Whilst patients with diabetes and diabetologists are well initiated to injectable therapies, the cardiovascular therapeutic arena has traditionally been dominated by oral agents. It is therefore important to examine the practical aspects of treating patients with these new lipid-lowering agents, to ensure they are optimally deployed in everyday clinical practice.

Keywords: Adherence; Cardiovascular risk; Compliance; Evolocumab; Lipid-lowering; PCSK9; Self-administration; Statins; Subcutaneous

\section{INTRODUCTION}

Efficacious pharmacotherapies can only unlock their benefits if they are associated with high acceptability and adherence among the patients to whom they are prescribed. In the context of an ageing population with multiple comorbidities and polypharmacy, the challenge of adherence 
and compliance is increasingly important. Whilst the cardiovascular $(\mathrm{CV})$ therapeutic area has benefited from a number of advances in drug development and device innovation, this brings the challenge of ensuring the ever-growing therapeutic armamentarium of evidence-based treatments are optimally used in real-world practice [1]. Cardiovascular risk reduction through lipid lowering represents one of the most evidence-rich areas of cardiology, and clinical medicine more broadly. The advent of several new and effective classes of therapy in this area, which have different modes of administration, brings the topic of adherence and patient-centric considerations to the forefront of strategies for modern cardiovascular disease (CVD). We here review the challenges of treatment adherence in cardiometabolic diseases, and explore how modern therapies and their administration can be optimized to ensure maximal adherence and benefit to patients.

\section{Compliance with Ethics Guidelines}

This article is based on previously conducted studies and does not involve any new studies of human or animal subjects performed by any of the authors.

\section{THE CHALLENGE OF ADHERENCE IN CARDIOVASCULAR PHARMACOLOGY}

As of 2010, individuals using five or more prescription drugs increased by $70 \%$ as compared to the previous decade [2], with $\mathrm{CV}$ drugs the most frequently used therapeutic group [3]. Current international guidelines aim to counter clinician inertia for the management of common CV risk factors, such as high blood pressure, and advocate the use of polypharmacy [4] when clinically indicated. For lipid lowering specifically, some have traditionally taken a more conservative view with respect to combination therapies. This was in part due to the risk-benefit ratio of non-statin therapies available at the time these guidelines were written [5]. This point will be discussed in more detail later [5]. The ESC/EASD Guidelines on diabetes, pre-diabetes, and CV diseases [6] emphasise the importance of patient-centred care to assist goal setting and self-management, and to implement behavioural strategies in conjunction with simplified dosing regimens to improve adherence. Polypharmacy is, however, associated with higher morbidity and costs. The use of multiple medications often leads to suboptimal drug use, with under-prescription or inappropriate prescriptions, low adherence and side effects. Cardiovascular drugs represent one of the most used pharmacologic groups [7] and the prescription of beta-blockers, angiotensin-converting enzyme (ACE)-inhibitors and anti-thrombotic agents have been largely responsible for the steep increase in polypharmacy in recent decades [8]. In a large national survey in the USA, hypertension was a predictor of polypharmacy and hydrochlorothiazide, atorvastatin and lisinopril were the most prescribed medications [9].

Although CV drugs are frequently associated with polypharmacy, several studies have reported their large-scale underuse $[10,11]$. The use of five or more drugs can often prove harmful, as it is associated with inappropriate prescriptions and use of medications, reduced adherence, and drug-drug interactions [3]. In primary and secondary prevention of CVD, taking multiple medications may often result in under-treatment and therefore increased risk of adverse outcomes $[12,13]$. Under-prescription is defined as a lack of drug treatment for a disease in which drug therapy is indicated and for which no contraindications exist [14]. Medication under-prescribing was particularly common in a study of older patients (average age 75 years) taking five or more drugs, with blood pressure-lowering agents, anticoagulants and lipid-lowering drugs the most underused drugs [11].

Inappropriate drug prescription increases costs, mainly by medication under-use and hospitalisations from adverse effects [15]. A treatment paradox also appears to exist, where those patients at highest risk and in most need of effective treatment are most likely to be non-adherent. Patterns of drug therapy and mortality risk were studied in patients with heart failure-patients with a greater 1-year risk of predicted death were less likely to take 
ACE-inhibitors, angiotensin receptor blockers (ARBs), and beta-blockers [13]. Similarly, compared to low-risk patients, a large retrospective cohort study in Canada found statin use was lower among high-risk patients with previous myocardial infarction [12].

\section{EVALUATING ADHERENCE AND PATIENT SATISFACTION SCORES}

Greater medication adherence is associated with improved clinical outcomes, prognostic benefits in overall risk and mortality, and improved cost-efficacy [16-22]. Treatment adherence includes both compliance and persistence: treatment compliance is influenced by the mode of administration and frequency of doses, persistence relates to the length of time the patient remains on treatment [23]. While self-reporting provides a simple, inexpensive, patient-centric approach for assessing medication adherence, this method is susceptible to patients providing socially desirable responses. Multi-item adherence scales have been designed to minimise this bias [24]. Many factors impact a patient's perception towards their medication, including both real and perceived benefits and harms, prior experience, and complexity of regimens, as well as perceptions of their illness, satisfaction with treatment, and personal preferences [25]. In order to deliver optimal treatment outcomes, patients must therefore receive the correct choice of medication, at the correct time [26]. Central to this concept of 'medicines optimisation' is the need to ensure patients are taking the medications they have been prescribed correctly, as well as preventing inappropriate use of medicines [26, 27]. Also, self-reported medication adherence has been found to be at least moderately correlated with adherence calculated using pharmacy fill and electronic monitoring [28].

\section{REGIMEN COMPLEXITY}

Complex regimens impact patient safety by presenting adherence challenges and increase the likelihood of drug-drug interactions. This may lead to serious clinical consequences from both medication under- and over-use. Further, complexity of medication regimens has been found to be an important predictor of a patient's ability to manage medications [29]. Studies found an association between complexity scores and important outcomes, including adherence, caregiver burden, quality of life, hospitalisations, and emergency department and physician visits. Hospitalisation itself has been shown to increase medication complexity, therein fueling a cycle of healthcare inefficiency [30, 31]. Studies often include regimen attributes (e.g. dosing frequency) in addition to number of medicines: current scales appear to focus on specific populations, such as human immunodeficiency virus (HIV) [32] and epilepsy [30], or specific drug classes. Reducing complexity of treatment regimens is advocated by the American Society of Health-Systems Pharmacists Pharmacy Practice Model Initiative [33], and the American Geriatrics Society guiding principles for the Care of Older Adults with Multimorbidity [34].

In a systematic review of complexity of regimens [35], frequency of administration showed the clearest agreement among scales, with increased frequency leading to increased complexity scores. The influence of multiple daily dosing on regimen complexity and therefore adherence is supported by a recent meta-analysis. Coleman et al. found that medication adherence, as measured by an electronic monitoring device, was significantly lower for 2-, 3-, and 4-times per day regimens, compared with once-daily dosing [36]. Prior adherence studies also support reduction in dosing frequency [36-38]. In a meta-analysis, DiMatteo and colleagues [39] reported higher adherence to treatment guidelines among patients in poorer health, but only for those conditions classified as less serious (e.g. hypertension). In contrast, in those conditions classified as serious (e.g. cancers), adherence was found to be lower for those in poorer health. This may be a consequence of severely declining health and associated functional limitations. There are a wealth of studies reporting the reduction in adherence associated with increasing treatment complexity-principally, the frequency of dosing necessitated, but 
also the route of administration, and other dosing requirements (e.g. timing with meals) [40-42].

\section{ADHERENCE ACCORDING TO MODE OF ADMINISTRATION}

There is increasing experience with the subcutaneous (SC) route of administration from biologics in malignancies and inflammatory diseases [43]. These have provided insights with respect to the practical use, convenience, and potential for self-administration of injectable medications, all of which influence healthcare resources and costs. When assessing patient preferences and satisfaction, it is also important to appreciate the different methods and delivery devices available for SC administration. A recent systematic review assessed patients' perspectives on SC administered self-injectable medications compared with other routes or methods of administration for the same medicines [44]: 85 studies met the inclusion criteria, which ranged from treatments for growth disorders, diabetes, multiple sclerosis, HIV, and migraine. Among studies comparing needle-free injector devices (NFIDs) with SC injections, there was significant preference towards NFIDs in terms of patient-rated ease of use [45], preference, or a desire to continue with the NFID at the end of the study [46]. In an adaptive conjoint analysis of users of growth hormone therapy, autoinjection generated higher utility when compared with prefilled syringes (PFS) [47]. In addition, a meta-analysis comparing patient perspectives of medication administration routes in several different disease states found increased satisfaction and preference for pen devices and autoinjectors as compared with needle and syringe, with respect to the ergonomics, convenience, and portability [44]. Further, there was no clear favorability between oral, SC, and intramuscular administration routes. Studies have demonstrated that compliance with oral bisphosphonate therapy is poor, with $50-75 \%$ of patients discontinuing treatment as early as the first year of therapy [48].

\section{LESSONS LEARNED FROM DIABETES MELLITUS}

Type 2 diabetes mellitus (T2DM), like dyslipidaemia, is a chronic disease for which the majority of daily management rests with the individual patient. Patient-related considerations around the acceptability of therapies should therefore play a central role in selecting medications, and have been shown to influence the success of long-term use and clinical outcomes [49]. A large proportion of adult patients with diabetes also exhibit blood LDL-C $\geq 100 \mathrm{mg} / \mathrm{dl}$ or used lipid-lowering medications [50]. Traditional therapies for diabetes are associated with problematic adverse events, specifically in respect to hypoglycaemia (sulphonylureas [SUs] or glinides, insulin) and weight gain (SUs, glinides, thiazolidinediones [TZDs] and insulin), which can reduce adherence [51-53].

The dissatisfaction of patients to insulin, in particular, which typically necessitates administration of multiple daily doses, led to the concept of "psychological insulin resistance" [54]. Unlike Type 1 Diabetes Mellitus (T1DM), in T2DM, patients will often have failed to achieve good blood glucose control with multiple oral agents before starting insulin. Patient misconceptions may exacerbate the reluctance for long-term insulin use, mistakenly associating insulin with uncontrolled disease, poorer outcomes and complications. The problem of adherence is, however, not unique to insulin and injectable antidiabetic medications: adherence rates for oral antidiabetic medications have ranged from 36 to $93 \%$ in the literature, with most studies reporting adherence in the range of $65-85 \%[55,56]$. Poor adherence to antidiabetic medications represents a barrier to optimal glycaemic control. A number of studies have demonstrated the link between reduced treatment adherence and poorer glycaemic control, and the associated increase in health care costs $[17,57,58]$. In the case of insulin, pen devices offer a more acceptable method of administration than conventional vial and syringe with respect to portability, convenience, ease of use, and reduced injection-site pain, 
with high levels of patient satisfaction and adherence [50, 59].

The complexity of medication management is one of the key considerations which impact the ability and willingness of patients with T2DM to initiate and adhere to prescribed therapies. When burdensome, this can serve as an obstacle to optimal self-care [51]. Studies examining the association between antidiabetic medication regimen complexity and antidiabetic medication adherence have shown regimens with less frequent dosing to be associated with increased adherence $[38,40]$. In the first phase of the Treating to Target in Type 2 Diabetes (4-T) study [60], patients with T2DM with suboptimal glycaemic control on metformin and sulfonylurea were randomised to the addition of a biphasic, prandial, or basal analogue insulin. The proportions of patients who withdrew from the study differed significantly among the groups: $5.1 \%$ in the biphasic insulin group ( 2 injections per day), $8.5 \%$ in the basal group ( 1 injection per day), with the highest withdrawal rates in the prandial group (3 injections per day) at $11.7 \%$. A specific analysis of the IMPROVE study (a multicentre nonrandomised observational study of the safety and efficacy of Biphasic Insulin Aspart 30 [NovoMix $30^{\circledR}$ ] in T2DM) applied the DiabMedSat to examine the impact of different factors on patient-reported treatment satisfaction [61]. Patients treated with NovoMix $30^{\circledR}$ reported improved treatment satisfaction, which was considered clinically meaningful to patients. In addition, regression analysis reported negative associations between weight gain and minor hypoglycemic events with satisfaction in each of the DiabMedSat domains, in addition to the total score. Achievement of haemoglobin A1c (HbA1c) levels was associated with greater satisfaction in Symptoms and Burden domains. Data from the French National Health and Wellness Survey reported that patients on insulin therapy were associated with a 33-fold higher odds of being adherent to their medication than those on oral bitherapy or tritherapy [62]. Further, insulin treatment was not associated with a reduction in quality of life.

Protease proprotein convertase subtilisin/ kexin type 9 (PCSK9) inhibitors for lipid lowering offer attractive and convenient dosing regimens, with some agents only requiring monthly administration. In this respect, novel incretin-based treatments for diabetes have a number of comparable qualities to offer their respective therapeutic area, without the need for daily dose adjustment or tight monitoring and less frequent dosing regimens. Glucagonlike peptide-1 receptor agonists (GLP-1RAs) represent a class of injectable antidiabetic medications recommended for use as monotherapy or in conjunction with other therapies in dual, triple, or more complex regimens [63]. There are several approved GLP-1RAs on the market, with well-established clinical efficacy and differing dosing regimen complexities.

Patient-reported outcomes (PROs) provide valuable insights into patient experience of using different therapies [64]. The Diabetes Treatment Satisfaction Questionnaire (DTSQ) uses 6 items to produce a 'total treatment satisfaction' score. A "change version" of the DTSQ (DTSQc) [65] was later developed to enables respondents to evaluate their current treatment in relation to their previous treatment, permitting comparison between agents. A systematic review of PROs largely utilising the DTSQ and/ or Impact of Weight on Quality of Life-Lite (IWQOL-Lite) found patients were satisfied overall with incretin-based therapies compared with traditional treatments [64]. Treatment satisfaction (including perceptions of convenience and flexibility) was heavily influenced by efficacy of glucose lowering, as well as weight loss and the low incidence of hypoglycaemia. These benefits offset any potential reticence about injections.

Secondary analyses of key trials of incretin-based therapies have assessed the influence of frequency and mode of administration on adherence and patient satisfaction. Switching from an oral agent to a SC drug was not associated with any reduction in patient satisfaction [66]: among injectables, once-daily regimens were preferred over twice-daily $[67,68]$, and once-weekly regimens had greater DTSQ scores related to 'willingness to continue' compared with twice-daily programs [69]. Convenience, flexibility and reductions in public distress were 
cited among the causative factors for this difference [69]. Real-world evidence from administrative claims data in the US also reported increased adherence (measured by the proportion of days covered [PDC]) in those treated with the least frequent regimen of GLP-1RAs, even after adjusting for potential confounders [70]. Indeed, studies examining the complexity of antidiabetic medication dosing regimens have reported that the frequency of dosing required can be more influential on adherence than pill burden [71]. When patients were asked to select between hypothetical treatments as part of a discrete-choice experiment, more injection-naïve T2DM patients opted for weekly injections rather than daily injections, with dosing frequency identified as the principal patient consideration for selecting GLP-1RA treatments [72].

Comparisons of injected liraglutide versus oral glimepiride in respect to patient satisfaction have been evaluated using the DTSQ and IWQOL-Lite [73], with similar total treatment satisfaction scores observed despite a greater incidence of nausea with the injectable treatments. In this instance, patients' appeared to prioritise their perceived benefits of reduced hypoglycaemia and weight loss. In a separate study, patients randomised to SC exenatide once weekly had increased total treatment satisfaction compared with those receiving oral sitagliptin or pioglitazone: analyses showed that improved HbA1c and weight loss induced by exenatide once weekly were key drivers in the improved treatment satisfaction in individuals with T2DM [74].

The data above indicate that the traditional perception that patients prefer oral rather than injectable medications may not hold true as, where there are discernible or perceived efficacy benefits, these appear to outweigh fear of injection and perceptions of reduced convenience and flexibility [75, 76]. This is particularly pertinent given the recent surge in large and well-conducted cardiovascular outcomes trials that have increased the evidence base for the efficacy or neutrality of anti-diabetic therapies on CV events: LEADER [77] for liraglutide; EMPA-REG OUTCOME for empagliflozin [78]; and ELIXA for lixisenatide [79]. In contrast, glargine has neutral effects on $\mathrm{CV}$ outcomes [80], and the glitazone class has been the subject of scrutiny with respect to cardiotoxicity (rosiglitazone being associated with a signal towards excess risk of severe cardiovascular disease or death from cardiovascular causes) [81]. If these data are communicated to patients, one might speculate that, based on the adherence discussions thus far, perceived efficacy differentiators would impact adherence.

\section{OPTIMISING DEPLOYMENT OF MODERN CV THERAPIES}

A number of population studies have reported the widespread failure in current real-world practice to meet lipid targets [82-85]. Secondary prevention data in those enrolled in the vascular protection (VP) and guidelines orientated approach to lipid lowering (GOALL) study indicated that around half of patients were not at-goal, with even fewer among the highest risk groups [86]. Statins provide efficacious lipid-lowering with an excellent safety profile and adverse skeletal muscle effects and myopathy representing the main side effects. Clinical trials report a $1.5-5 \%$ incidence of statin-induced myopathy $[87,88]$, although real-world evidence suggests a higher frequency [89].

Perhaps the most damaging consequence of AEs in patients taking statins is the potential to reduce compliance: negative views concerning side effects with statin therapy have implications for adherence on a population level and cause significant harm in terms of preventable CV events and death [90]. Indeed, despite the efficacy of statins in reducing $\mathrm{CV}$ events in both primary and secondary prevention, a significant portion of patients with atherosclerotic cardiovascular disease (ASCVD) do not receive statins or are treated with suboptimal doses. Data from US federal health insurance programmes have demonstrated low statin use even among high-risk patients with established coronary heart disease (CHD), with figures ranging between 53 and 59\% [91]. Similar low adherence has been observed across indications, including patients at high risk of CHD [92] and in those with Framingham risk 
scores $>20 \%$, with statins only used in one-fifth of patients. Even in the acute setting, among patients who filled a prescription for a statin following a CHD event, only $27 \%$ filled a prescription for a high-intensity statin after their hospital discharge [93], despite clear international guidance advocating this approach [5]. Similar results have been observed in European countries [29]: among patients who do initiate a statin, data from primary care show that $40-75 \%$ discontinue within the first year of treatment [94-96].

Statin underuse arises from a number of different factors, with physician [97] and patient inertia [98] playing a central role. The reluctance of patients to initiate or adhere to statin treatment is due, in part, to concerns regarding potential toxicities. Together, these factors lead to a collective therapeutic inertia, which has been reported to be as high as $43 \%$, and does not spare those at very high risk with established ischaemic heart disease and dyslipidaemia [97]. Physician questionnaires have also revealed very conservative prescribing behaviours, with a reluctance to escalate lipid-lowering management in patients despite grossly uncontrolled LDL-C levels [99]. Inadequate physician education with respect to the benefit-risk profile of statins may contribute to this behaviour [100].

Whilst statin-associated muscle symptoms are an important contributor to treatment discontinuation [101], a number of other symptoms have been attributed to interruption of stain treatment, including hair loss, gastrointestinal symptoms and sleep disturbance, often without confirmed causality [102]. In many cases, patient apprehension and concerns regarding potential toxicity and adverse events drive non-adherence, rather than actually having experienced any symptoms [101]. Indeed, a meta-analysis of the side effects of statins reported that adverse effects commonly attributed to statins (e.g. headache) were often reported in equal numbers to those treated with placebo [103]. Patient surveys have shown that the patient apprehension around statins is further worsened by uncertainty about the benefits of these agents [104]. It should be acknowledged that inherent challenges do exist with adherence in dyslipidaemia, as the risk is asymptomatic [104]. Although there is emerging evidence around the potential of genetic polymorphisms relevant to the 3-hydroxy-3-methylglutaryl coenzyme A reductase (HMG-CoA-R) pathway contributing to 'statin resistance' [105], it is likely that suboptimal adherence is the principal factor responsible for patients' variable responses to statins [106, 107].

Regardless of aetiology, adherence to statin therapy is suboptimal [108]. Thus, in patients not at-goal for lipid lowering, or intolerant to statins, and particularly in those at high or very high CV risk, alternative therapies are indicated. For these patients, the options include switching to another statin, or selecting non-statin lipid-lowering drugs. More recent trial data for therapies targeting secreted circulating PCSK9 or the Niemann-Pick C1-like 1 (NPC1L1) protein suggest that incremental lowering beyond that achieved with statin treatment is possible [109-111].

\section{CLINICAL UTILITY OF PCSK9 INHIBITORS}

Two monoclonal antibodies directed against PCSK9 are approved for treatment of hyperlipidaemia and mixed dyslipidaemia [117, 118]. International guidelines for lipid lowering have key differences in their recommendations. The 2013 ACC/AHA guideline on the treatment of blood cholesterol to reduce atherosclerotic CV risk in adults [5] identified statin benefit groups, and focused on the initiation and maintenance of high- or moderate-intensity statin therapy. While non-statin therapies were deemed not to be justified at the time these guidelines were written, due to their benefit-risk profile, this was principally based on evidence from niacin in the AIM-HIGH [119] and HPS-2 THRIVE [120] trials, and fibrates in ACCORD-Lipid [121] and Field [122]. The National Lipid Association (NLA) Expert Panel [123] recommends nonstatin therapy be considered when excessive circulating atherogenic cholesterol persists despite appropriate lifestyle and statin therapy. The ESC/EAS consensus statement [63] recommends the use of PCSK9 inhibitors in severe 
familial hypercholesterolaemia $(\mathrm{FH})$ without ASCVD, and heterozygous $\mathrm{FH}$ (He FH) with maximally tolerated statin plus ezetimibe and LDL-C $>5.0 \mathrm{mmol} / \mathrm{l}(>200 \mathrm{mg} / \mathrm{dl})$, or those with LDL-C $>4.5 \mathrm{mmol} / \mathrm{l}(>175 \mathrm{mg} / \mathrm{dl})$ and 1 additional risk factor indicative of very high $\mathrm{CV}$ risk. With the advent of PCSK9 inhibiters, an ACC task force recently released a consensus report to update the 2013 recommendations for non-statin therapy [124]: in patients who cannot achieve $\geq 50 \%$ LDL-C reduction or a 30 to $<50 \%$ LDL-C reduction with statins and dietary interventions (including fibre supplements and phytosterol supplements), the use of several non-statin therapies (including ezetimibe, bile acid sequestrants, and PCSK9 inhibitors) is recommended, depending on the patient group under consideration. With respect to PCSK9 inhibitors, those patients taking maximally tolerated statin therapy who have clinical ASCVD, or patients without clinical ASCVD and baseline LDL-C levels $\geq 190 \mathrm{mg} / \mathrm{dL}$ are potential candidates.

In addition to medical societies, and in lieu of definitive results from the ongoing outcome studies, several national health systems and insurance companies have reimbursed PCSK9 inhibitors for selected patient populations. The UK National Institute for Health and Care Excellence (NICE) recommends evolocumab [125] and alirocumab [126] in patients on maximal tolerated lipid-lowering therapy with primary non-familial hypercholesterolaemia or mixed dyslipidaemia in the following circumstances: those with high risk of CVD and LDL-C persistently $>4.0 \mathrm{mmol} / \mathrm{l}$, and those with very high CVD risk and LDL-C persistently $>3.5 \mathrm{mmol} / \mathrm{l}$. In primary heterozygous-familial hypercholesterolaemia without CVD, evolocumab and alirocoumab are recommended only if LDL-C is persistently $>5.0 \mathrm{mmol} / \mathrm{l}$, or in patients with CVD where LDL-C is persistently $>3.4 \mathrm{mmol} / \mathrm{l}$, again despite maximal tolerated lipid-lowering therapy. While limited real-world data on these agents exist, one study from the US has reported on a small sample size treated with evolocumab and alirocumab [127]: following a multidisciplinary approach to patient selection and documentation, in the majority of patients, these agents were successfully approved by the insurance companies. Among patients treated with a PCSK9 inhibitor, 80\% had been treated as add-on therapy to a statin (with or without ezetimibe), and $20 \%$ as monotherapy. Through monthly phone calls from speciality pharmacists, $97 \%$ of these patients reported continued adherence to therapy at 1 year of treatment, with only $11 \%$ reporting any missed injections at all during this period.

With consideration to the importance of dosing simplicity and adherence, and the likelihood that a large proportion of patients will receive PCSK9 inhibitors in combination with another lipid-lowering therapy, and the relative novelty of self-administering SC medication in this patient population, understanding patients' perspectives around using injectable treatments is critical.

\section{EVOLOCUMAB}

Evolocumab is currently approved for SC administration using monthly (QM) or biweekly (Q2W) dosing [117, 128]. The Amgen trial program for evolocumab, the "Program to Reduce LDL-C and cardiovascular Outcomes Following Inhibition of PCSK9 In different pOpulations (PROFICIO)", consists of phase 2 and 3 studies which evaluated the safety and efficacy of evolocumab in patients with hypercholesterolaemia and mixed dyslipidaemia, in addition to a number of ongoing studies examining efficacy and safety with respect to atherosclerotic burden and outcomes in secondary prevention (ClinicalTrials.gov, NCT01813422, and NCT01984424).

In the evolocumab outcomes study (NCT01764633), when added to background statins, evolocumab lowered LDL-C by $59 \%$ to a median of $30 \mathrm{mg} / \mathrm{dL}$ (least squares mean at week 48 ), and significantly reduced the risk of cardiovascular events compared with placebo (median follow-up, 2.2 years) [129]. Administration of evolocumab in different settings was tested in the PROFICIO program. In phase 2 studies [130], evolocumab was administered in the clinic by a healthcare practitioner. In 
contrast, in the phase 3 studies [114-116, 131], the first one or two doses (in addition to the final dose) were administered in the clinic (either by site staff, the patient, or caregivers) and further doses were administered at home, by the caregiver or patient. Safety was assessed through reports of adverse events related to the drug or device. However, these studies were not designed to specifically test the feasibility of self-administration of evolocumab in the home setting.

\section{Frequency of Administration}

OSLER-2 [132] is an ongoing, open-label extension study of evolocumab phase 3 studies to evaluate the longer-term safety and efficacy of evolocumab in patients with hypercholesterolaemia. In OSLER-2, patients have the choice to receive evolocumab either $\mathrm{Q} 2 \mathrm{~W}$ or QM. Of 4764 patients receiving at least one dose of treatment during a qualifying parent study, 4581 (96\%) completed the study and became eligible for OSLER-2, and 3478 patients enrolled into OSLER-2 [132]. Figure 1 provides a schematic of the OSLER-2 study design and recruitment from parent studies. Patients dosed QM received three injections as a single treatment (equalling $420 \mathrm{mg}$ total). During parent studies, 2318 patients were randomised to evolocumab+standard-of-care (SOC), with an average follow-up period of 11 months. Of this group, $945(41 \%)$ were initially randomised to Q2W dosing, of which 70\% chose to continue with Q2W dosing and 30\% opted to switch to QM dosing. Of those 1373 (59\%) in parent studies who were randomised to a QM regimen, $74 \%$ chose to continue and $26 \%$ decided to change to the Q2W regimen. Only $2 \%$ of the Q2W regimen and 2\% of QM patients did not receive any further doses following the first day of administration. Following initial decisions regarding dosing preference, patients did not generally choose to change their regimen further during on-going treatment $(8 \%$ of $\mathrm{Q} 2 \mathrm{~W}$ patients switched to QM dosing and 5\% of QM patients switched to Q2W dosing). When given the option to change dosing regimens during OSLER-2, the majority of patients chose to continue with the dosing schedule they were assigned in the parent study, and stayed on their chosen dose in the first year of OSLER-2. Following the first open-label dose, very few patients dropped out of the study. This observation suggests patient acceptance of either a lower-volume/more-frequent or higher-volume/less-frequent regimen once preference was established.

\section{Comparison of Pre-Filled Syringe (PFS) Versus On-Body Devices}

In the phase 3 studies, evolocumab was administered as a $140-\mathrm{mg} / \mathrm{mL}$ solution in either a PFS or an autoinjector [113-116, 131, 133]. Trials have demonstrated evolocumab reduces LDL-C consistently across different populations. While administration at home and in a clinic setting were tested in the phase 3 studies, these studies did not specifically evaluate the feasibility of at-home administration. Patients who enrolled with hypercholesterolaemia or mixed dyslipidaemia on statin therapy and with or without ezetimibe received evolocumab in the at-home setting. In the THOMAS-1 study, 149 patients were randomised to self-administer evolocumab $140 \mathrm{mg}$ Q2W over 6 weeks using either a PFS or a SureClick ${ }^{\circledR}$ autoinjector (ClinicalTrials.gov, NCT01849497) [112]. Each PFS or autoinjector is for single use only and consists of a 1-mL solution in a single use pre-filled pen, of which the entire contents are injected per use for simplicity of administration. In the THOMAS-2 study, 164 patients were randomised to evolocumab $420 \mathrm{mg}$ QM administered over 12 weeks in either a SureClick ${ }^{\circledR}$ autoinjector or an automated minidoser (ClinicalTrials.gov, NCT01879319) [112]. The addition of a monthly dosing option was intended to accommodate patient convenience. The THOMAS-2 study was the first phase 3 study to use the automated minidoser device, which is a single-use, disposable, on-body electromechanical device that administers $420 \mathrm{mg}$ of evolocumab in $3.5 \mathrm{ml}$ over approximately $9 \mathrm{~min}$ [112]. Figure 2 includes an illustration of the three devices. In these two clinical studies, the first self-administration occurred in the in-clinic 


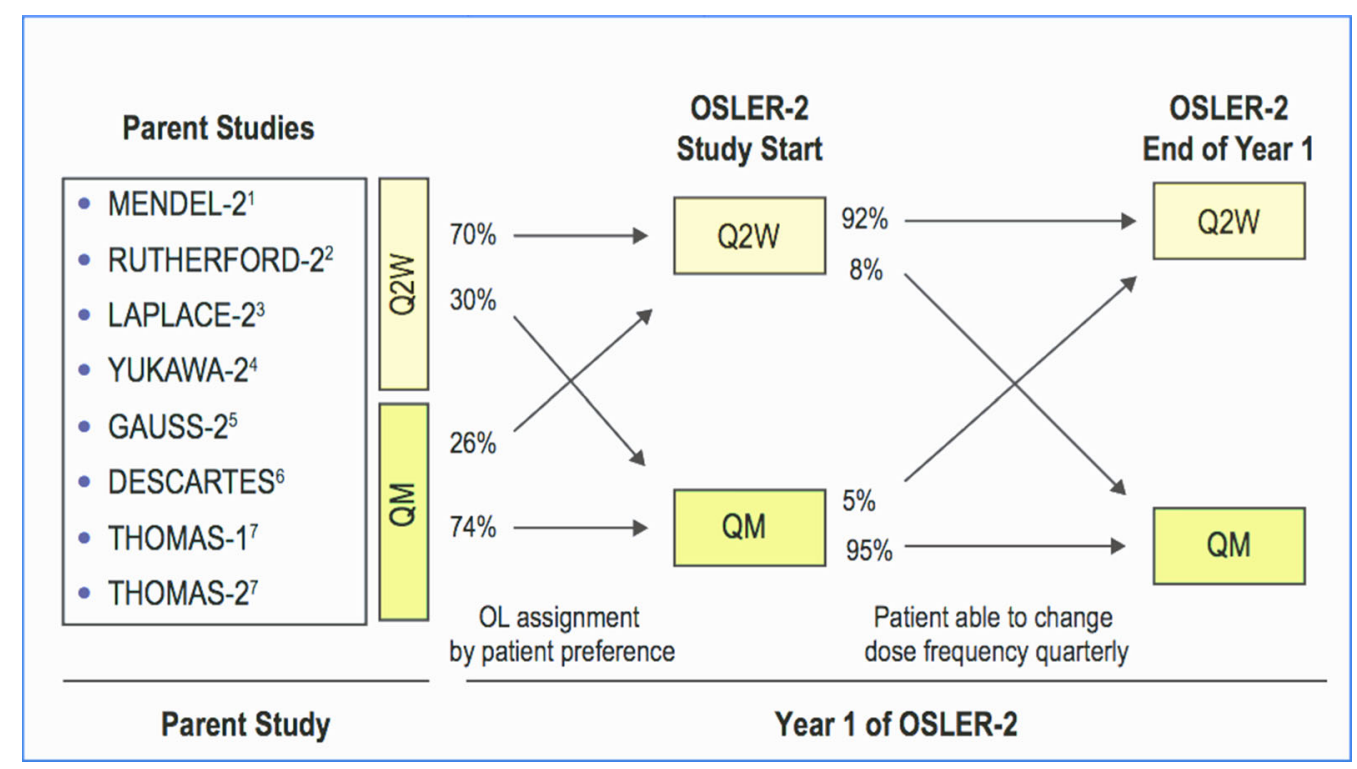

Fig. 1 Study design and recruitment for OSLER-2. Adapted from Koren et al., 2016 [132]. OL open-labelled, $Q 2 W$ biweekly, $Q M$ monthly. Percentages reflect the

setting, and two more were performed in the at-home setting. Patients were successful in self-administering evolocumab in the at-home setting in approximately $95 \%$ of attempts, and experienced LDL-C reductions from baseline to week 6 or the mean of weeks 10 and 12 of approximately $65 \%$. Rates of successful self-administration and LDL-C reduction were similar across dosing schedules and study devices. Evolocumab exhibits nonlinear pharmacokinetics and, as such, $420 \mathrm{mg}$ QM produces clinically equivalent changes in lipid parameters and tolerance compared with 140-mg Q2W dosing [134]. Adverse events (AEs) were similar between randomised groups and generally mild in severity. Four adverse device effects were reported: 2 injection site reactions occurred in one patient who used the automated minidoser, 2 patients in the autoinjector group experienced pain in extremity or injection-site haematoma [112]. AEs in the THOMAS studies were similar to AEs of the overall PROFICIO population [111, 114-116, 131]. Patient disposition of the studies and reasons for discontinuation are shown in Fig. 3. proportion of patients continuing on dose frequency or changing to alternative dose frequency

\section{Evolocumab in the Home-Use Setting}

The LDL-C reduction and safety observed in evolocumab clinical [111, 114-116, 131] provides a strong rationale to offer eligible patients this injectable to be initiated and administered in the at-home setting. The randomised studies, THOMAS-1 and THOMAS-2, were designed specifically to evaluate the ability of patients to inject evolocumab with different devices in the context of at-home use [112]. Following suitable training in use and drug administration with the device, almost all patients in these studies could administer evolocumab successfully at home, and increased success with repeat subsequent injections. The profound LDL-C reduction seen at follow-up in both studies further signals the reliability of self-administrations. The devices tested were safe and well tolerated. These findings provide compelling evidence that evolocumab can be successfully administered by patients at home without the need for supervision from a healthcare professional, provided that appropriate training is given. 

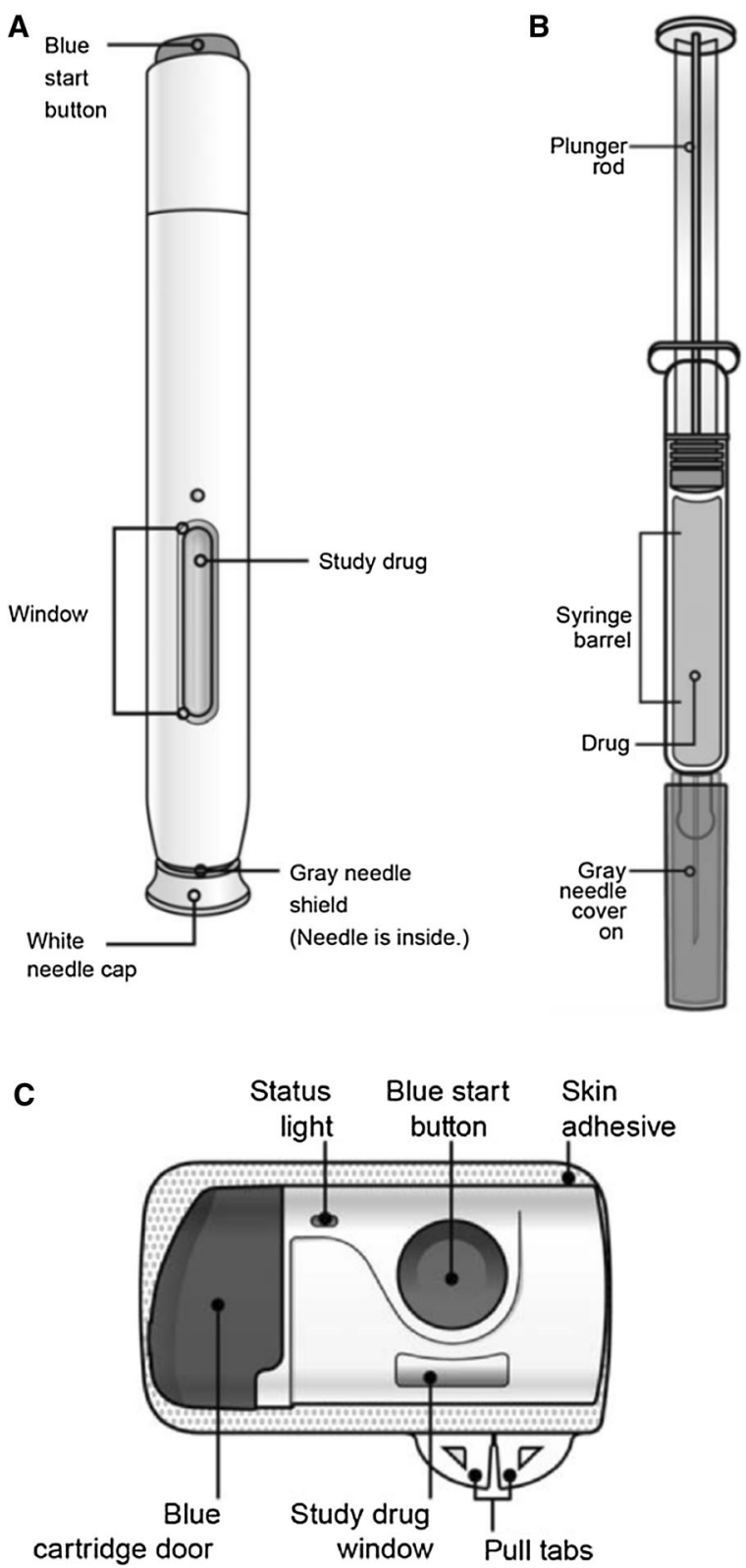

Fig. 2 Diagrams of a autoinjector, b prefilled syringe, and c automated minidoser (on-body infusor) [112]

Based on the results of the THOMAS studies summarised above, the US prescribing information for evolocumab was recently updated [135] to include the single-use, disposable, on-body electromechanical device (known as the Pushtronex ${ }^{\mathrm{TM}}$ system on-body infusor with prefilled cartridge in the US) in addition to the PFS. All devices are approved in the US for at-home administration by patients or their caregivers with the relevant training $[117,135]$. In Europe, the Committee for Medicinal Products for Human Use adopted a positive opinion for the automated minidoser on 16 December 2016. Evolocumab is approved at doses of $140 \mathrm{mg}$ Q2W or $420 \mathrm{mg}$ QM [128]; these two dosing regimens provide equivalent LDL-C reductions over time [108] and are offered to accommodate patient preference [128]. The 140-mg injections can be administered either with a single-use PFS or single-use prefilled SureClick ${ }^{\circledR}$ autoinjector/pen [117], whilst the 420-mg dose can be administered over 9 min by using the single-use Pushtronex ${ }^{\mathrm{TM}}$ system on-body infusor with prefilled cartridge (US only, 117, 135), or by giving three injections consecutively within $30 \mathrm{~min}$ using the single-use prefilled SureClick ${ }^{\circledR}$ autoinjector/pen or single-use PFS [117]. The recommended SC dose in patients with homozygous familial hypercholesterolaemia (HoFH) is $420 \mathrm{mg} \quad \mathrm{QM}$ $[117,128]$. According to the EU label, evolocumab treatment at a dose of $420 \mathrm{mg}$ Q2W may be initiated in $\mathrm{HoFH}$ patients on apheresis to correspond with their apheresis schedule [117]. If a clinically meaningful response is not achieved in $\mathrm{HoFH}$ patients by week 12, dose frequency can be up-titrated to $420 \mathrm{mg}$ Q2W [117].

\section{ALIROCUMAB}

\section{Frequency of Administration}

Alirocumab was initially approved for Q2W SC administration, with a starting dose of $75 \mathrm{mg}$, which could be increased to a maximum dosage of $150 \mathrm{mg}$ Q2W should the LDL-C response be inadequate [136]. In Europe, alirocumab monthly dosing [110] was also approved, based on results from CHOICE I [111] which demonstrated the viability of alirocumab at $300 \mathrm{mg}$ Q4W in patients with hypercholesterolaemia at moderate-to-very-high cardiovascular risk requiring LDL-C-lowering treatment who were previously on maximally tolerated statin or no statin, either alone or in combination with other lipid-lowering therapies. Significant 


\section{THOMAS-1}

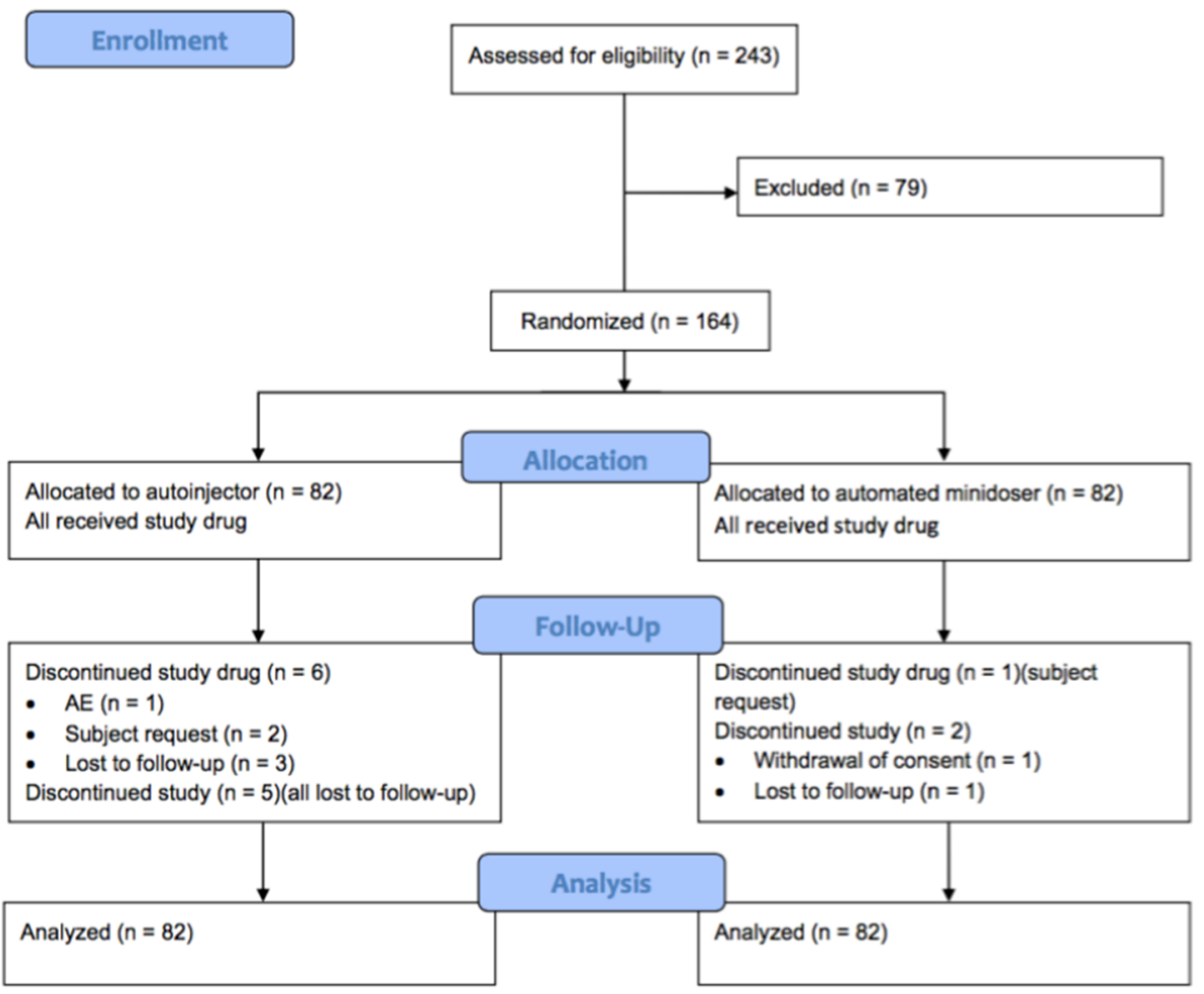

THOMAS-2

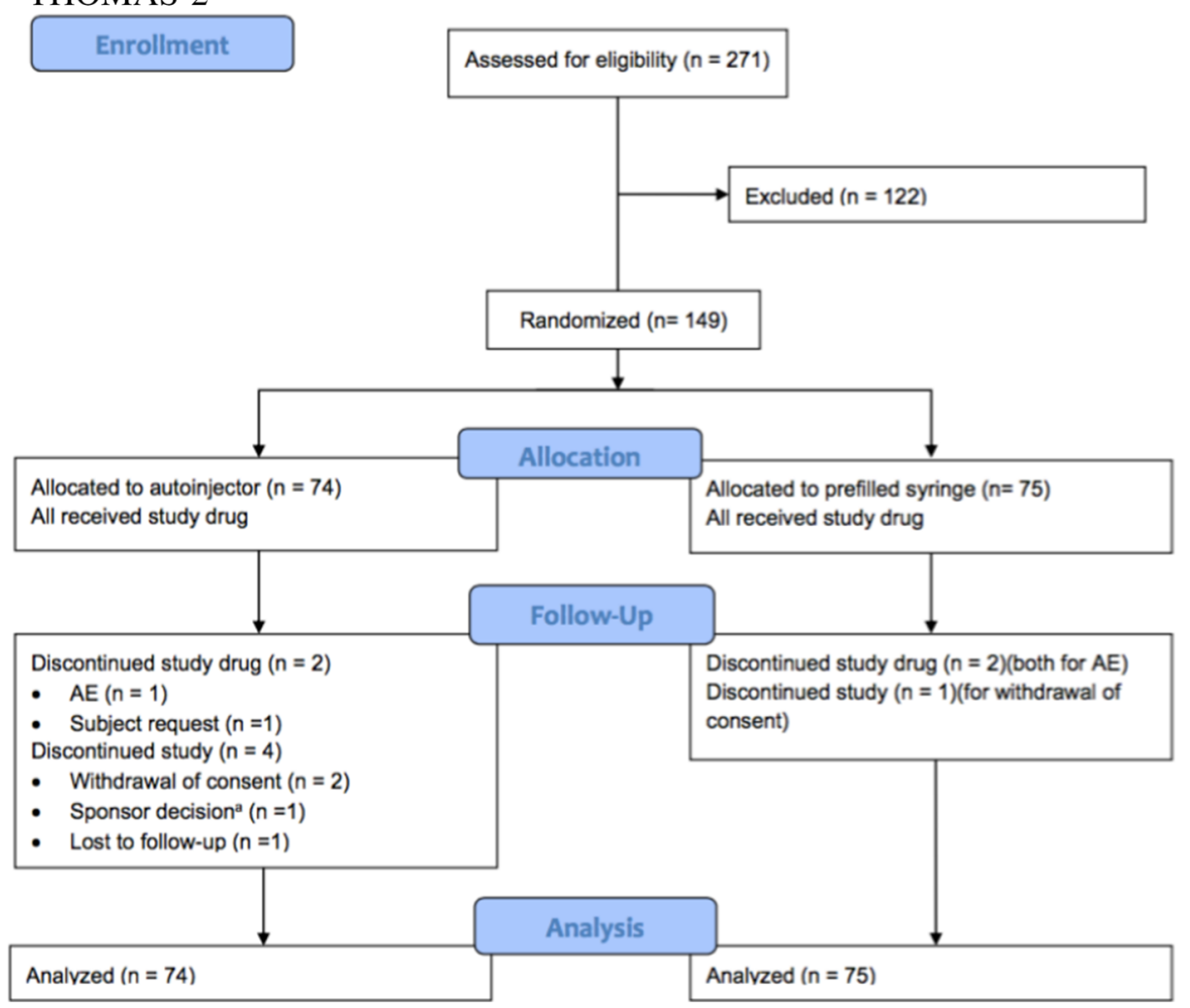


4 Fig. 3 THOMAS-1 and THOMAS-2 patient disposition. Taken from Dent et al. 2006 [112]

LDL-C reductions from baseline to week 24 were seen with alirocumab at $300 \mathrm{mg}$ Q4W versus placebo, with acceptable levels of treatment-emergent adverse events. ODYSSEY CHOICE II [112] evaluated alirocumab $150 \mathrm{mg}$ Q4W in patients not on statins (mostly as a consequence of statin-associated muscle symptoms), with inadequately controlled hypercholesterolaemia receiving treatment with fenofibrate, ezetimibe, or diet alone. Alirocumab $150 \mathrm{mg}$ Q4W and $75 \mathrm{mg}$ Q2W achieved comparable least-squares mean LDL-C changes from baseline to week 24 ( -51.7 and $-53.5 \%$, respectively), with similar treatment-emergent adverse events. As such, the updated EU label [110] recommends $75 \mathrm{mg}$ Q2W SC as a starting dose, and patients requiring larger LDL-C reduction ( $>60 \%$ ) have the option to start on $150 \mathrm{mg}$ Q2W or $300 \mathrm{mg}$ Q4W. The dose of alirocumab can be individualised based on patient characteristics such as baseline LDL-C level, goal of therapy, and response. If additional LDL-C reduction is needed in patients treated with $75 \mathrm{mg}$ once every 2 weeks or $300 \mathrm{mg}$ once every 4 weeks (monthly), the dosage may be adjusted to the maximum dosage of $150 \mathrm{mg}$ once every 2 weeks.

Treatment adherence with alirocumab was recently assessed in a pooled analysis from six double-blind Phase 3 trials from the ODYSSEY program [137]. Overall adherence was calculated for each patient as $100 \%$ - (\% days with below-planned dosing $+\%$ days with aboveplanned dosing). In 4197 patients (mean exposure, 71.9 weeks), overall mean adherence was $97.9 \%$, with a mean 1.9 and $0.2 \%$ days belowplanned and above-planned dosing, respectively, over a period of 52 weeks or more. In this pooled analysis, there was a 3-day therapeutic window around the scheduled administration date in which the drug could be administered without affecting the magnitude of LDL-C lowering.

\section{Alirocumab in the Home-Use Setting}

The Injection-Treatment Acceptance Questionnaire (I-TAQ) was recently utilised to test patient-reported outcomes in individuals taking alirocumab. Participants were recruited through purposeful sampling from either a randomised double-blind, placebo-controlled clinical trial or an open-label extension trial for alirocumab. The questionnaire consists of 17 items (with a further 5 added following the first interview) and was tested through 3 rounds of qualitative interviews in high CV risk patients [114]. Concepts of treatment acceptance that emerged included perceived efficacy of the treatment, acceptance of side effects, injection self-efficacy, injection convenience, and overall acceptance [114]. Although three-quarters of patients recalled feeling apprehensive when administering their first alirocumab injection (approximately half of whom had a previous fear of needles), all patients reported feeling confident in administering their most recent injection. Most patients (79\%) did not report the injection to have any impact on their psychological/ emotional wellbeing: only 1 patient (3\%) reported feeling scared of the needle and 1 patient (3\%) had stress associated with remembering when to take the injection. Overall, 13\% of patients actually reported a positive change in their psychological wellbeing after the treatment due to the improvements in test results. Perceived efficacy of the treatment was defined as the patient's belief that the treatment was effectively treating their condition. Of the patients interviewed, two-thirds did not know whether the treatment was working because they had not seen their LDL-C levels; such patients, therefore, relied on their own perception regarding whether their treatment was effective. Conversely, those patients recruited from the open-label study had access to their results and therefore had knowledge of their 
LDL-C levels as an indicator of efficacy. Perceived efficacy of the treatment was reported to substantially influence patients' acceptance and attitudes toward long-term use and adherence. The patients discussed how convenient they found administering the injection, specifically practical aspects such as the scheduling and frequency of doses, remembering doses, managing missed doses, storage of the treatment, and the time taken to prepare and administer the treatment. Almost all (93\%) patients found it easy to fit the injection into their schedule, comparing it to other routine activities of daily living such as "brushing my teeth". All patients took the injection at home and reported this to be the most convenient place to administer the treatment, the majority of whom $(72 \%)$ spontaneously reported using a reminder to help them take their injection at the correct time (e.g. setting a timer).

\section{OTHER PCSK9 INHIBITORS IN DEVELOPMENT}

Inclisiran is an investigational chemically synthesised small interfering RNA designed to target PCSK9 messenger RNA. It is being studied at dosing regimens of 200, 300, or $500 \mathrm{mg}$ SC every 90 or 180 days. In a recently completed phase 2 multicentre double-blind placebo-controlled trial [138] of 501 patients at high risk for $\mathrm{CV}$ disease and elevated LDL-C levels, the primary end point of change from baseline LDL-C at 180 days was met, with least-squares mean reductions of $27.9-41.9 \%$ after a single dose at 90 days of inclisiran and $35.5-52.6 \%$ after 2 doses over 180 days. The infrequent dosing required with this agent is attractive from an administration perspective and phase 3 studies are ongoing to further evaluate efficacy in relevant patient groups.

\section{CONCLUSION}

Polypharmacy in CVD is a natural byproduct of our success in preventing mortalities in the setting of acute CV events, thus necessitating chronic primary and secondary therapeutic prevention. Polypharmacy is, however, associated with a number of challenges-most notably adherence. A wealth of patient-reported outcomes and adherence data from other therapeutic areas, of which the GLP-1RAs in T2DM are arguably the most relevant, reveal a high acceptance of injectable medications, in particular if regimen complexity is improved (i.e. reduced dosing frequency), the device is simple and patients are made aware of the associated clinical efficacy of the agents being administered. Despite the well-known safety and efficacy of statin therapies, an unacceptably high number of patients in both primary and secondary prevention fail to meet lipid targets. In addition, a proportion of patients will be poorly adherent, in part due to intolerance. Against this background, the PCSK9 inhibitors bring opportunities and challenges. Their reduced dosing frequency with patient-managed injections assisted by simple and effective administration tools and devices will likely improve adherence. The pharmacodynamics of these injectable therapies and the reduced frequency of their administration also provide a degree of forgiveness if the scheduled dosing date is missed by a few days, still permitting good LDL-C lowering over time, in contrast to oral agents where a missed dose often equates to a day of lost coverage. However, while their licensed indication is broad, their reimbursement and initial use will likely be as add-on therapy to maximal tolerated statins (with or without ezetimibe). Optimising the practical aspects of drug prescription and administration and shifting the focus of care to patient-centric considerations should therefore represent a critical agenda in future efforts in CV disease and risk prevention.

\section{ACKNOWLEDGEMENTS}

Sponsorship, publication fees and the cost of open access for this article were sponsored by Amgen (Europe). All named authors meet the International Committee of Medical Journal Editors (ICMJE) criteria for authorship for this manuscript, take responsibility for the integrity of the 
work as a whole, and have given final approval for the version to be published. All authors had full access to all of the data in this study and take complete responsibility for the integrity of the data and accuracy of the data analysis. The authors thank Dr Kaivan Khavandi and Dr Jack Brownrigg of London et al Scientific Communications Ltd, who provided medical writing assistance. Funding for this medical writing support was provided by Amgen (Europe) $\mathrm{GmbH}$. Editorial support was provided by Carine Thual and Claire Desborough of Amgen (Europe) GmbH.

Disclosures. Ricardo Dent was an employee of Amgen (Europe) $\mathrm{GmbH}$ at the time of this work and owns stocks in Amgen and Esperion Therapeutics. Franck Boccara reports a research grant from Amgen, speaker fees from AstraZeneca, Merck-Sharpe Dohme, and participation in advisory boards for Amgen, Sanofi, Gilead, ViiV Healthcare. Luis Ruilope has received speaker/advisory fees from Amgen. Paul Valensi has received speaker fees from Merck Santé, GlaxoSmithKline, Merck Sharp Dohme, Novo Nordisk, Novartis, Pierre Fabre, Abbott, Eli-Lilly, Bayer, Bristol Myers Squibb, and AstraZeneca, research grants from Merck Santé, GlaxoSmithKline, Novo Nordisk, Bayer, Abbott, Bristol Myers Squibb, and AstraZeneca, and reports participation in Expert Committees for Amgen, GlaxoSmithKline, Novo Nordisk, Boehringer Ingelheim, AstraZeneca, Bristol Myers Squibb, Daiichi-Sankyo, and Lilly, and is an expert for HAS and AFSSAPS in France.

Compliance with Ethics Guidelines. This article is based on previously conducted studies and does not involve any new studies of human or animal subjects performed by any of the authors.

Open Access. This article is distributed under the terms of the Creative Commons Attribution-NonCommercial 4.0 International License (http://creativecommons.org/licenses/ by-nc/4.0/), which permits any noncommercial use, distribution, and reproduction in any medium, provided you give appropriate credit to the original author(s) and the source, provide a link to the Creative Commons license, and indicate if changes were made.

\section{REFERENCES}

1. Ho PM, Bryson CL, Rumsfeld JS. Medication adherence: its importance in cardiovascular outcomes. Circulation. 2009;119(23):3028-35.

2. Gu Q, Dillon CF, Burt VL. Prescription drug use continues to increase: US prescription drug data for 2007-2008. NCHS Data Brief. 2010;42:1-8.

3. Volpe M, Chin D, Paneni F. The challenge of polypharmacy in cardiovascular medicine. Fundam Clin Pharmacol. 2010;24(1):9-17.

4. Mancia G, De Backer G, Dominiczak A, Cifkova R, Fagard R, Germano G, et al. 2007 ESH-ESC practice guidelines for the management of arterial hypertension: ESH-ESC task force on the management of arterial hypertension. J Hypertens. 2007;25(9):1751-62.

5. Stone NJ, Robinson JG, Lichtenstein AH, Bairey Merz CN, Blum CB, Eckel RH, et al. ACC/AHA guideline on the treatment of blood cholesterol to reduce atherosclerotic cardiovascular risk in adults: a report of the American College of Cardiology/ American Heart Association Task Force on Practice Guidelines. J Am Coll Cardiol. 2014;63(25 Pt B):2889-934.

6. Authors/Task Force M, Ryden L, Grant PJ, Anker SD, Berne C, Cosentino F, et al. ESC Guidelines on diabetes, pre-diabetes, and cardiovascular diseases developed in collaboration with the EASD: the Task Force on diabetes, pre-diabetes, and cardiovascular diseases of the European Society of Cardiology (ESC) and developed in collaboration with the European Association for the Study of Diabetes (EASD). Eur Heart J. 2013;34(39):3035-87.

7. Jörgensen T, Johansson S, Kennerfalk A, Wallander M-A, Svärdsudd K. Prescription drug use, diagnoses, and healthcare utilization among the elderly. Ann Pharmacother. 2001;35(9):1004-9.

8. Haider S, Johnell K, Thorslund M, Fastbom J. Trends in polypharmacy and potential drug-drug interactions across educational groups in elderly patients in Sweden for the period 1992-2002. Int J Clin Pharmacol Ther. 2007;45(12):643-53.

9. Kaufman DW, Kelly JP, Rosenberg L, Anderson TE, Mitchell AA. Recent patterns of medication use in the ambulatory adult population of the United States: the Slone survey. JAMA. 2002;287(3):337-44.

10. Hajjar ER, Cafiero AC, Hanlon JT. Polypharmacy in elderly patients. Am J Geriatr Pharmacother. 2007;5(4):345-51.

11. Steinman MA, Seth Landefeld C, Rosenthal GE, Berthenthal D, Sen S, Kaboli PJ. Polypharmacy and 
prescribing quality in older people. J Am Geriatr Soc. 2006;54(10):1516-23.

12. Ko DT, Mamdani M, Alter DA. Lipid-lowering therapy with statins in high-risk elderly patients: the treatment-risk paradox. JAMA. 2004;291(15):1864-70.

13. Lee DS, Tu JV, Juurlink DN, Alter DA, Ko DT, Austin PC, et al. Risk-treatment mismatch in the pharmacotherapy of heart failure. JAMA. 2005;294(10):1240-7.

14. Aronson JK. A prescription for better prescribing. $\mathrm{Br}$ J Clin Pharmacol. 2006;61(5):487-91.

15. Johnson JA, Bootman JL. Drug-related morbidity and mortality: a cost-of-illness model. Arch Intern Med. 1995;155(18):1949-56.

16. Curkendall SM, Thomas N, Bell KF, Juneau PL, Weiss AJ. Predictors of medication adherence in patients with type 2 diabetes mellitus. Curr Med Res Opin. 2013;29(10):1275-86.

17. Asche C, LaFleur J, Conner C. A review of diabetes treatment adherence and the association with clinical and economic outcomes. Clin Ther. 2011;33(1):74-109.

18. Balkrishnan R, Rajagopalan R, Camacho FT, Huston SA, Murray FT, Anderson RT. Predictors of medication adherence and associated health care costs in an older population with type 2 diabetes mellitus: a longitudinal cohort study. Clin Ther. 2003;25(11):2958-71.

19. Boswell KA, Cook CL, Burch SP, Eaddy MT, Cantrell CR. Associating medication adherence with improved outcomes: a systematic literature review. Am J Pharm Benefits. 2012;4(4):e97-108.

20. Ho PM, Rumsfeld JS, Masoudi FA, McClure DL, Plomondon ME, Steiner JF, et al. Effect of medication nonadherence on hospitalization and mortality among patients with diabetes mellitus. Arch Intern Med. 2006;166(17):1836-41.

21. Jha AK, Aubert RE, Yao J, Teagarden JR, Epstein RS. Greater adherence to diabetes drugs is linked to less hospital use and could save nearly $\$ 5$ billion annually. Health Aff. 2012;31(8):1836-46.

22. Stuart BC, Simoni-Wastila L, Zhao L, Lloyd JT, Doshi JA. Increased persistency in medication use by US Medicare beneficiaries with diabetes is associated with lower hospitalization rates and cost savings. Diabetes Care. 2009;32(4):647-9.

23. Adachi J, Lynch N, Middelhoven H, Hunjan M, Cowell $\mathrm{W}$. The association between compliance and persistence with bisphosphonate therapy and fracture risk: a review. BMC Musculoskel Disord. 2007;8(1):97.

24. Morisky DE, Ang A, Krousel-Wood M, Ward HJ. Predictive validity of a medication adherence measure in an outpatient setting. J Clin Hypertens. 2008;10(5):348-54.

25. Hemingway S. Medicines adherence-involving patients in decisions about prescribed medicines and supporting adherence: NICE clinical guideline 76. Mental Health Nurs (Online). 2009;29(2):10.

26. National Institute for Health and Care Excellence. Medicines optimisation: the safe and effective use of medicines to enable the best possible outcomes. 2015. Available at https://www.nice.org.uk/ guidance/ng5. Accessed 20 Sept 2016.

27. Clifford S, Barber N, Elliott R, Hartley E, Horne R. Patient-centred advice is effective in improving adherence to medicines. Pharm World Sci. 2006;28(3):165-70.

28. Shi L, Liu J, Fonseca V, Walker P, Kalsekar A, Pawaskar M. Correlation between adherence rates measured by MEMS and self-reported questionnaires: a meta-analysis. Health Qual Life Outcomes. 2010;8(1):1.

29. Maddigan SL, Farris KB, Keating N, Wiens CA, Johnson JA. Predictors of older adults' capacity for medication management in a self-medication program a retrospective chart review. J Aging Health. 2003;15(2):332-52.

30. Dilorio C, Yeager K, Shafer PO, Letz R, Henry T, Schomer DL, et al. The epilepsy medication and treatment complexity index: reliability and validity testing. J Neurosci Nurs. 2003;35(3):155-62.

31. Elliott RA, O'Callaghan CJ. Impact of hospitalisation on the complexity of older patients' medication regimens and potential for regimen simplification. J Pharm Pract Res. 2011;41(1):21-5.

32. Martin S, Wolters PL, Calabrese SK, Toledo-Tamula MA, Wood LV, Roby G, et al. The antiretroviral regimen complexity index: a novel method of quantifying regimen complexity. J Acquir Immune Defic Syndr. 2007;45(5):535-44.

33. Pharmacists ASoH-S. Pharmacy practice model summit. Executive summary. Am J Health Syst Pharm. 2011;68(12):1079-85.

34. Boyd C, McNabney M, Brandt N. Patient-centered care for older adults with multiple chronic conditions: a stepwise approach from the American Geriatrics Society: American Geriatrics Society Expert Panel on the Care of Older Adults with Multimorbidity. J Am Geriatr Soc. 2012;60:1957-68. 
35. Paquin AM, Zimmerman KM, Kostas TR, Pelletier L, Hwang A, Simone M, et al. Complexity perplexity: a systematic review to describe the measurement of medication regimen complexity. Expert Opin Drug Saf. 2013;12(6):829-40.

36. Coleman CI, Limone B, Sobieraj DM, Lee S, Roberts MS, Kaur R, et al. Dosing frequency and medication adherence in chronic disease. J Manag Care Pharm. 2012;18(7):527-39.

37. Corsonello A, Pedone C, Lattanzio F, Lucchetti M, Garasto S, Carbone C, et al. Regimen complexity and medication nonadherence in elderly patients. Ther Clin Risk Manag. 2009;5:209.

38. Ingersoll KS, Cohen J. The impact of medication regimen factors on adherence to chronic treatment: a review of literature. J Behav Med. 2008;31(3):213-24.

39. DiMatteo MR, Haskard KB, Williams SL. Health beliefs, disease severity, and patient adherence: a meta-analysis. Med Care. 2007;45(6):521-8.

40. Dezii CM, Kawabata H, Tran M. Effects of once-daily and twice-daily dosing on adherence with prescribed glipizide oral therapy for type 2 diabetes. South Med J. 2002;95(1):68-72.

41. Jin J, Sklar GE, Oh VMS, Li SC. Factors affecting therapeutic compliance: a review from the patient's perspective. Ther Clin Risk Manag. 2008;4(1):269.

42. Pollack M, Chastek B, Williams SA, Moran J. Impact of treatment complexity on adherence and glycemic control: an analysis of oral antidiabetic agents. JCOM. 2010;17(6):257-65

43. Hughes M. Prefilled syringes: injecting the end-user's perspec-tive. Drug Deliv Technol. 2010;10:18-23.

44. Ridyard CH, Dawoud DM, Tuersley LV, Hughes DA. A systematic review of patients' perspectives on the subcutaneous route of medication administration. Patient. 2016.

45. Harris M, Joy R, Larsen G, Valyi M, Walker E, Frick LW, et al. Enfuvirtide plasma levels and injection site reactions using a needle-free gas-powered injection system (Biojector). AIDS. 2006;20(5):719-23.

46. Boyd MA, Truman M, Hales G, Anderson J, Dwyer DE, Carr A. Short communication A randomized study to evaluate injection site reactions using three different enfuvirtide delivery mechanisms (the OPTIONS study). Antivir Ther. 2008;13:449-53.

47. Ahmed SF, Smith W, Blamires C. Facilitating and understanding the family's choice of injection device for growth hormone therapy by using conjoint analysis. Arch Dis Child. 2008;93(2):110-4.

48. Kothawala P, Badamgarav E, Ryu S, Miller RM, Halbert R, editors. Systematic review and meta-analysis of real-world adherence to drug therapy for osteoporosis. Mayo Clinic Proceedings; 2007: Elsevier.

49. Garcia-Perez LE, Alvarez M, Dilla T, Gil-Guillen V, Orozco-Beltran D. Adherence to therapies in patients with type 2 diabetes. Diabetes Ther. 2013;4(2):175-94.

50. Molife C, Lee LJ, Shi L, Sawhney M, Lenox SM. Assessment of patient-reported outcomes of insulin pen devices versus conventional vial and syringe. Diabetes Technol Ther. 2009;11(8):529-38.

51. Odegard PS, Capoccia K. Medication taking and diabetes a systematic review of the literature. Diabetes Educator. 2007;33(6):1014-29.

52. Pi-Sunyer FX. The impact of weight gain on motivation, compliance, and metabolic control in patients with type 2 diabetes mellitus. Postgrad Med. 2009;121(5):94-107.

53. Pollack MF, Purayidathil FW, Bolge SC, Williams SA. Patient-reported tolerability issues with oral antidiabetic agents: associations with adherence; treatment satisfaction and health-related quality of life. Diabetes Res Clin Pract. 2010;87(2):204-10.

54. Polonsky WH, Jackson RA. What's so tough about taking insulin? Addressing the problem of psychological insulin resistance in type 2 diabetes. Clin Diabetes. 2004;22(3):147-50.

55. Cramer JA. A systematic review of adherence with medications for diabetes. Diabetes Care. 2004;27(5):1218-24.

56. Rubin RR. Adherence to pharmacologic therapy in patients with type 2 diabetes mellitus. Am J Med. $2005 ; 118(5): 27-34$.

57. Salas M, Hughes D, Zuluaga A, Vardeva K, Lebmeier $\mathrm{M}$. Costs of medication nonadherence in patients with diabetes mellitus: a systematic review and critical analysis of the literature. Value Health. 2009;12(6):915-22.

58. Wild $\mathrm{H}$. The economic rationale for adherence in the treatment of type 2 diabetes mellitus. Am J Manag Care. 2012;18(3 Suppl):S43-8.

59. Asche CV, Shane-McWhorter L, Raparla S. Health economics and compliance of vials/syringes versus pen devices: a review of the evidence. Diabetes Technol Ther. 2010;12(S1). 
60. Holman RR, Farmer AJ, Davies MJ, Levy JC, Darbyshire JL, Keenan JF, et al. Three-year efficacy of complex insulin regimens in type 2 diabetes. $\mathrm{N}$ Engl J Med. 2009;361(18):1736-47.

61. Brod M, Valensi P, Shaban JA, Bushnell DM, Christensen TL. Patient treatment satisfaction after switching to NovoMix(R) 30 (BIAsp 30) in the IMPROVE study: an analysis of the influence of prior and current treatment factors. Qual Life Res. 2010;19(9):1285-93.

62. Reach G, Le Pautremat V, Gupta S. Determinants and consequences of insulin initiation for type 2 diabetes in France: analysis of the National Health and Wellness Survey. Patient Prefer Adherence. 2013;7:1007-23.

63. Garber A, Abrahamson M, Barzilay J, Blonde L, Bloomgarden Z, Bush M, et al. AACE comprehensive diabetes management algorithm 2013. Endocrine Pract. 2013;19(2):327-36.

64. Davies M, Speight J. Patient-reported outcomes in trials of incretin-based therapies in patients with type 2 diabetes mellitus. Diabetes Obes Metab. 2012;14(10):882-92.

65. Bradley C. Diabetes treatment satisfaction questionnaire. Diabetes Care. 1999;22(3):530.

66. Drucker DJ, Buse JB, Taylor K, Kendall DM, Trautmann M, Zhuang D, et al. Exenatide once weekly versus twice daily for the treatment of type 2 diabetes: a randomised, open-label, non-inferiority study. Lancet. 2008;372(9645):1240-50.

67. Buse JB, Rosenstock J, Sesti G, Schmidt WE, Montanya $\mathrm{E}$, Brett $\mathrm{JH}$, et al. Liraglutide once a day versus exenatide twice a day for type 2 diabetes: a 26-week randomised, parallel-group, multinational, open-label trial (LEAD-6). Lancet. 2009;374(9683):39-47.

68. Buse JB, Sesti G, Schmidt WE, Montanya E, Chang $\mathrm{C}-\mathrm{T}, \mathrm{Xu} \mathrm{Y}$, et al. Switching to once-daily liraglutide from twice-daily exenatide further improves glycemic control in patients with type 2 diabetes using oral agents. Diabetes Care. 2010;33(6):1300-3.

69. Norman GR, Sloan JA, Wyrwich KW. Interpretation of changes in health-related quality of life: the remarkable universality of half a standard deviation. Med Care. 2003;41(5):582-92.

70. Johnston SS, Nguyen H, Felber E, Cappell K, Nelson JK, Chu BC, et al. Retrospective study of adherence to glucagon-like peptide-1 receptor agonist therapy in patients with type 2 diabetes mellitus in the United States. Adv Ther. 2014;31(11):1119-33.

71. Zhang L, Zakharyan A, Stockl KM, Harada AS, Curtis BS, Solow BK. Mail-order pharmacy use and medication adherence among Medicare Part D beneficiaries with diabetes. J Med Econ. 2011;14(5):562-7.

72. Hauber AB, Nguyen H, Posner J, Ervin C, LaRue S, Kalsekar I, editors. Patient preferences for frequency of glucagon-like peptide-1 receptor agonist (GLP-1RA) injections in the treatment of type 2 diabetes. ISPOR 19th Annual International Meeting; 2014.

73. Hermansen K, Kolotkin RL, Hammer M, Zdravkovic M, Matthews D. Patient-reported outcomes in patients with type 2 diabetes treated with liraglutide or glimepiride, both as add-on to metformin. Primary Care Diabetes. 2010;4(2):113-7.

74. Best JH, Rubin RR, Peyrot M, Li Y, Yan P, Malloy J, et al. Weight-related quality of life, health utility, psychological well-being, and satisfaction with exenatide once weekly compared with sitagliptin or pioglitazone after 26 weeks of treatment. Diabetes Care. 2011;34(2):314-9.

75. Pratley R, Nauck M, Bailey T, Group L-D-S. Switching from the DPP-4 inhibitor sitagliptin to the human GLP-1 analog liraglutide further improves glycemic control and weight loss in patients with type 2 diabetes. Diabetes. 2011;60(suppl 1):A307-8.

76. Montanya E, Pratley R, Nauck M, Bailey T, Garber A, Filetti S, et al. Switching from sitagliptin to liraglutide, in combination with metformin, improves treatment satisfaction in patients with type 2 diabetes. Diabetes. 2011;60(Suppl 1):A307.

77. Marso SP, Daniels GH, Brown-Frandsen K, Kristensen P, Mann JF, Nauck MA, et al. Liraglutide and Cardiovascular Outcomes in Type 2 Diabetes. N Engl J Med. 2016.

78. Zinman B, Lachin JM, Inzucchi SE. Empagliflozin, cardiovascular outcomes, and mortality in type 2 diabetes. N Engl J Med. 2016;374(11):1094.

79. Pfeffer MA, Claggett B, Diaz R, Dickstein K, Gerstein $\mathrm{HC}$, Kober LV, et al. Lixisenatide in patients with type 2 diabetes and acute coronary syndrome. N Engl J Med. 2015;373(23):2247-57.

80. Investigators OT, Gerstein HC, Bosch J, Dagenais GR, Diaz R, Jung $\mathrm{H}$, et al. Basal insulin and cardiovascular and other outcomes in dysglycemia. N Engl J Med. 2012;367(4):319-28.

81. Nathan DM. Rosiglitazone and cardiotoxicityweighing the evidence. $\mathrm{N}$ Engl $\mathrm{J}$ Med. 2007;357(1):64-6.

82. Krobot KJ, Yin DD, Alemao E, Steinhagen-Thiessen E. Real-world effectiveness of lipid-lowering therapy in male and female outpatients with coronary heart 
disease: relation to pre-treatment low-density lipoprotein-cholesterol, pre-treatment coronary heart disease risk, and other factors. Eur J Cardiovasc Prev Rehabil. 2005;12(1):37-45.

83. Antiochos P, Marques-Vidal P, Waeber G, Vollenweider P. Five year trends in dyslipidaemia prevalence and management in Switzerland: the CoLaus study. Nutr Metab Cardiovasc Dis. 2015;25(11):1007-15.

84. Bongard V, Dallongeville J, Arveiler D, Ruidavets $\mathrm{J}-\mathrm{B}$, Amouyel P, Wagner A, et al. Attainment of low-density lipoprotein cholesterol target in the French general population according to levels of cardiovascular risk: insights from the MONA LISA study. Arch Cardiovasc Dis. 2013;106(2):93-102.

85. Bruckert E, Ferrières J. Evidence supporting primary prevention of cardiovascular diseases with statins: gaps between updated clinical results and actual practice. Arch Cardiovasc Dis. 2014;107(3):188-200.

86. Yan AT, Yan RT, Tan M, Hackam DG, Leblanc KL, Kertland $\mathrm{H}$, et al. Contemporary management of dyslipidemia in high-risk patients: targets still not met. Am J Med. 2006;119(8):676-83.

87. Joy TR, Hegele RA. Narrative review: statin-related myopathy. Ann Intern Med. 2009;150(12):858-68.

88. Law M, Rudnicka AR. Statin safety: a systematic review. Am J Cardiol. 2006;97(8):S52-60.

89. Fernandez G, Spatz ES, Jablecki C, Phillips PS. Statin myopathy: a common dilemma not reflected in clinical trials. Cleve Clin J Med. 2011;78(6):393-403.

90. Nielsen SF, Nordestgaard BG. Negative statin-related news stories decrease statin persistence and increase myocardial infarction and cardiovascular mortality: a nationwide prospective cohort study. Eur Heart J. 2015:ehv641.

91. Bittner V, Deng L, Rosenson RS, Taylor B, Glasser SP, Kent ST, et al. Trends in the use of nonstatin lipid-lowering therapy among patients with coronary heart disease: a retrospective cohort study in the medicare population 2007 to 2011. J Am Coll Cardiol. 2015;66(17):1864-72.

92. Gamboa CM, Safford MM, Levitan EB, Mann DM, Yun H, Glasser SP, et al. Statin underuse and low prevalence of LDL-C control among US adults at high risk of coronary heart disease. Am J Med Sci. 2014;348(2):108-14.

93. Rosenson RS, Kent ST, Brown TM, Farkouh ME, Levitan EB, Yun $\mathrm{H}$, et al. Underutilization of high-intensity statin therapy after hospitalization for coronary heart disease. J Am Coll Cardiol. 2015;65(3):270-7.

94. Simons LA, Levis G, Simons J. Apparent discontinuation rates in patients prescribed lipid-lowering drugs. Med J Aust. 1996;164(4):208-11.

95. Avorn J, Monette J, Lacour A, Bohn RL, Monane M, Mogun $\mathrm{H}$, et al. Persistence of use of lipid-lowering medications: a cross-national study. JAMA. 1998;279(18):1458-62.

96. Blackburn DF, Dobson RT, Blackburn JL, Wilson TW, Stang MR, Semchuk WM. Adherence to statins, beta-blockers and angiotensin-converting enzyme inhibitors following a first cardiovascular event: a retrospective cohort study. Can J Cardiol. 2005;21(6):485-8.

97. Lázaro P, Murga N, Aguilar D, Hernández-Presa MA, Investigators IS. Therapeutic inertia in the outpatient management of dyslipidemia in patients with ischemic heart disease. The inertia study. Rev Esp Cardiol (English Edition). 2010;63(12):1428-37.

98. Phillips LS, Branch WT, Cook CB, Doyle JP, El-Kebbi IM, Gallina DL, et al. Clinical inertia. Ann Intern Med. 2001;135(9):825-34.

99. Krempf M, Simpson RJ, Ramey DR, Brudi P, Giezek $\mathrm{H}$, Tomassini JE, et al. Patient and physician factors influence decision-making in hypercholesterolemia: a questionnaire-based survey. Lipids Health Dis. 2015;14(1):45.

100. Banach M, Stulc T, Dent R, Toth PP. Statin non-adherence and residual cardiovascular risk: there is need for substantial improvement. Int J Cardiol. 2016;225:184-96.

101. Stroes ES, Thompson PD, Corsini A, Vladutiu GD, Raal FJ, Ray KK, et al. Statin-associated muscle symptoms: impact on statin therapy-European Atherosclerosis Society Consensus Panel Statement on Assessment, Aetiology and Management. Eur Heart J. 2015;36(17):1012-22.

102. Banach M, Rizzo M, Toth PP, Farnier M, Davidson $\mathrm{MH}$, Al-Rasadi $\mathrm{K}$, et al. Statin intolerance-an attempt at a unified definition. Position paper from an International Lipid Expert Panel. Arch Med Sci. 2015;11(1):1-23.

103. Goldacre B. Meta-analysis of side effects of statins shows need for trial transparency. BMJ. 2014;348:g2940.

104. Fung V, Sinclair F, Wang H, Dailey D, Hsu J, Shaber R. Patients' perspectives on nonadherence to statin therapy: a focus-group study. Perm J. 2010;14(1):4-10. 
105. Reiner Z. Resistance and intolerance to statins. Nutr Metab Cardiovasc Dis. 2014;24(10):1057-66.

106. Superko HR, Momary KM, Li Y. Statins personalized. Med Clin North Am. 2012;96(1):123-39.

107. Stone NJ. Reducing residual risk in secondary prevention of cardiovascular disease. Circulation. 2012;125(16):1958-60.

108. Pirillo A, Catapano AL. Statin intolerance: diagnosis and remedies. Curr Cardiol Rep. 2015;17(5):27.

109. Cannon CP, Blazing MA, Giugliano RP, McCagg A, White JA, Theroux $P$, et al. Ezetimibe added to statin therapy after acute coronary syndromes. N Engl J Med. 2015;372(25):2387-97.

110. Robinson JG, Farnier M, Krempf M, Bergeron J, Luc G, Averna M, et al. Efficacy and safety of alirocumab in reducing lipids and cardiovascular events. N Engl J Med. 2015;372(16):1489-99.

111. Sabatine MS, Giugliano RP, Wiviott SD, Raal FJ, Blom DJ, Robinson J, et al. Efficacy and safety of evolocumab in reducing lipids and cardiovascular events. N Engl J Med. 2015;372(16):1500-9.

112. Dent R, Joshi R, Djedjos CS, Legg J, Elliott M, Geller $\mathrm{M}$, et al. Evolocumab lowers LDL-C safely and effectively when self-administered in the at-home setting. SpringerPlus. 2016;5(1):1.

113. Kiyosue A, Honarpour N, Kurtz C, Xue A, Wasserman SM, Hirayama A. A phase 3 study of evolocumab (AMG 145) in statin-treated japanese patients at high cardiovascular risk. Am J Cardiol. 2016;117(1):40-7.

114. Koren MJ, Lundqvist P, Bolognese M, Neutel JM, Monsalvo ML, Yang J, et al. Anti-PCSK9 monotherapy for hypercholesterolemia: the MENDEL-2 randomized, controlled phase III clinical trial of evolocumab. J Am Coll Cardiol. 2014;63(23):2531-40.

115. Raal FJ, Stein EA, Dufour R, Turner T, Civeira F, Burgess L, et al. PCSK9 inhibition with evolocumab (AMG 145) in heterozygous familial hypercholesterolaemia (RUTHERFORD-2): a randomised, double-blind, placebo-controlled trial. Lancet. 2015;385(9965):331-40.

116. Stroes E, Colquhoun D, Sullivan D, Civeira F, Rosenson RS, Watts GF, et al. Anti-PCSK9 antibody effectively lowers cholesterol in patients with statin intolerance: the GAUSS-2 randomized, placebo-controlled phase 3 clinical trial of evolocumab. J Am Coll Cardiol. 2014;63(23):2541-8.

117. European Medicines Agency. Repatha (evolocu$\mathrm{mab}$ ): EU summary of product characteristics. 2016.
http://www.ema.europa.eu/docs/en_GB/document_ library/EPAR_-_Product_Information/human/0037 66/WC500191398.pdf Accessed 20 September 2016.

118. European Medicines Agency. Praluent (alirocumab): EU summary of product characteristics. 2016. Accessed 20 September 2016. Available at: http:// www.ema.europa.eu/docs/en_GB/document_library/ EPAR_-_Product_Information/human/003882/WC50 0194521.pdf.

119. Investigators A-H, Boden WE, Probstfield JL, Anderson T, Chaitman BR, Desvignes-Nickens P, et al. Niacin in patients with low HDL cholesterol levels receiving intensive statin therapy. $\mathrm{N}$ Engl J Med. 2011;365(24):2255-67.

120. Group HTC. HPS2-THRIVE randomized placebo-controlled trial in 25673 high-risk patients of ER niacin/laropiprant: trial design, pre-specified muscle and liver outcomes, and reasons for stopping study treatment. Eur Heart J. 2013;34(17):1279-91.

121. Group AS, Ginsberg HN, Elam MB, Lovato LC, Crouse JR 3rd, Leiter LA, et al. Effects of combination lipid therapy in type 2 diabetes mellitus. N Engl J Med. 2010;362(17):1563-74.

122. Keech A, Simes RJ, Barter P, Best J, Scott R, Taskinen $\mathrm{MR}$, et al. Effects of long-term fenofibrate therapy on cardiovascular events in 9795 people with type 2 diabetes mellitus (the FIELD study): randomised controlled trial. Lancet. 2005;366(9500):1849-61.

123. Jacobson TA, Ito MK, Maki KC, Orringer CE, Bays $\mathrm{HE}$, Jones $\mathrm{PH}$, et al. National Lipid Association recommendations for patient-centered management of dyslipidemia: part 1-executive summary. J Clin Lipidol. 2014;8(5):473-88.

124. Writing C, Lloyd-Jones DM, Morris PB, Ballantyne CM, Birtcher KK, Daly DD Jr, et al. 2016 ACC expert consensus decision pathway on the role of non-statin therapies for LDL-cholesterol lowering in the management of atherosclerotic cardiovascular disease risk: a report of the American College of cardiology task force on clinical expert consensus documents. J Am Coll Cardiol. 2016;68(1):92-125.

125. National Institute for Health and Care Excellence 2016. Evolocumab for treating primary hypercholesterolemia and mixed dyslipidemia Accessed May 2017; available at: https://www.nice.org.uk/ guidance/ta394.

126. National Institute for Health and Care Excellence 2016. Alirocumab for treating primary hypercholesterolemia and mixed dyslipidemia. Accessed May 2017 and availabel at: https://www.nice.or-g. uk/guidance/ta393. 
127. Sathiyakumar V, Martin SS, Jones S, Quinn J, Green R, Lesko A, et al. Real-world PCSK9i experience: the importance of a multidisciplinary approach. J Clin Lipidol. 2017;11(3):803.

128. US FDA: Drug Databases (approved drug products). Repatha (evolocumab). Highlights of prescribing information [BLA 125522]. Accessed September 2016. Available at: http://www.accessdata.fda.gov/ drugsatfda_docs/label/2015/125522s000lbl.pdf.

129. Sabatine MS, Giugliano RP, Keech AC, Honarpour N, Wiviott SD, Murphy SA, et al. Evolocumab and clinical outcomes in patients with cardiovascular disease. N Engl J Med. 2017;376(18):1713-22.

130. Stein EA, Giugliano RP, Koren MJ, Raal FJ, Roth EM, Weiss R, et al. Efficacy and safety of evolocumab (AMG 145), a fully human monoclonal antibody to PCSK9, in hyperlipidaemic patients on various background lipid therapies: pooled analysis of 1359 patients in four phase 2 trials. Eur Heart J. 2014;35(33):2249-59.

131. Robinson JG, Nedergaard BS, Rogers WJ, Fialkow J, Neutel JM, Ramstad D, et al. Effect of evolocumab or ezetimibe added to moderate-or high-intensity statin therapy on LDL-C lowering in patients with hypercholesterolemia: the LAPLACE-2 randomized clinical trial. JAMA. 2014;311(18):1870-83.

132. Koren MJ, Djedjos C, Ma Y, Somaratne R, Bolognese M. The Osler-2 study: patients' preferences and compliance with biweekly or monthly dosing during treatment of hypercholesterolemia with evolocumab [abstract]. J Am Coll Cardiol. 2016;67(13_S):1995.

133. Blom DJ, Hala T, Bolognese M, Lillestol MJ, Toth PD, Burgess L, et al. A 52-week placebo-controlled trial of evolocumab in hyperlipidemia. $\mathrm{N}$ Engl J Med. 2014;370(19):1809-19.

134. Stein EA, Koren M, Honarpour N, Kurtz C, Yang J, Wasserman $\mathrm{S}$, et al. Clinical equivalence of evolocumab $140 \mathrm{mg}$ every two weeks and $420 \mathrm{mg}$ monthly dosing regimens: a pooled analysis of 3146 patients in phase 3 studies. J Am Coll Cardiol. 2015;65(10_S).

135. US FDA: Drug Databases (approved drug products). Repatha (evolocumab). Supplemental approval letter 2016 [BLA 125522/S-001]; Accessed September 2016. Available at: http://www.accessdata.fda.gov/ drugsatfda_docs/appletter/2016/125522Orig1s001, s004ltr.pdf.

136. US FDA: Drug Databases (approved drug products). Praluent (alirocumab). Highlights of prescribing information [BLA 125559]. Accessed September 2016. Available at: http://www.accessdata.fda.gov/ drugsatfda_docs/label/2015/125559Orig1s000lbledt. pdf.

137. Farnier M, Colhoun HM, Sasiela WJ, Edelberg J, Asset G, Robinson JG. Treatment adherence to the proprotein convertase subtilisin/kexin type 9 inhibitor alirocumab in six odyssey phase 3 clinical studies with treatment duration of 52-104 weeks [abstract]. Presented at 84th EAS Congress 2016, Austria. OT05 Workshop (Late Breaking: Clinical Science).

138. Ray KK, Landmesser U, Leiter LA, Kallend D, Dufour $\mathrm{R}$, Karakas $\mathrm{M}$, et al. Inclisiran in patients at high cardiovascular risk with elevated LDL cholesterol. N Engl J Med. 2017;376(15):1430-40. 